\title{
On the Ancient Vocational Assessment System for Secretaries and Contemporary Enlightenments
}

\author{
WANG Yue $1, a,{ }^{*}$, LI Xin Lai', b, WEI Ji Hong ${ }^{2, c}$ \\ ${ }^{1}$ Department of Culture Media ,Shaanxi Youth Vocational College, Xi'an, Shaanxi, China \\ 2Petro China Changqing Oilfield Company, Xi'an, Shaanxi, China \\ a30204470@qq.com,blixl_cq@petrochina.com.cn, ${ }^{c} 85454789$ @qq.com
}

Keywords: Secretary, Assessment System, Innovation

\begin{abstract}
Along with the rapid development of modern society, the quantity of secretaries needed by society is rising year by year. The huge demand brings about opportunity and impetus for the vigorous development of secretary vocation but is also accompanied by such phenomena as varying professional quality of secretary personnel, increasingly serious post accidie mentality, and so forth. How to establish a scientific and rational vocational assessment system for secretaries has become a pressing issue that needs to be addressed. To ensure the overall quality of secretary team and the efficient running of secretary agency, the rulers of all ancient dynasties in China established vocational assessment systems for secretaries and constantly improved and innovated them in the long-term process of implementation. The research on the ancient vocational assessment system for secretaries is of important reference significance to the establishment and innovation of contemporary assessment system for the same.
\end{abstract}

\section{Introduction}

Chinese "secretary", literally meaning secret book, referred at first to the secret library in royal palace and later specially to an official position and relevant government office in charge of classics compilation and in control of documents and atlases, which was mainly responsible for recording what the emperor said, administering government affairs, preparing handling documents, and keeping archives; knowing the conditions at the lower levels, conveying orders, and playing a role as an intermediate between upper and lower levels; receiving petitioning officials and common people; and dealing with routine work of government office and other assigned tasks.

The ancient vocational assessment system for secretaries is an important component of secretary system. Since the hereditary cultivation of the Xia, Shang, and Zhou Dynasties, secretary selection had gone through multiple forms, including study in specialized school[1], imperial examination, examination of the Boxue Hongci Section, and cultivation by private institutions for staff training[2], and the selection criteria included patriotic loyalty, courage to write down the truth and give advice righteously, devotion to duty, incorruptibility, political reliability, secret keeping, honesty and trustworthiness, mastery of extensive knowledge, adeptness in writing, familiarity with punishment names, and good health. Secretaries also had to receive strict assessments from time to time during work. Those certified to be excellent in the assessments would be prompted, whereas unqualified ones would be punished or even face criminal penalty. Such a vocational supervision and assessment system was set up to urge secretaries to work with due diligence and better serve the ruling class. The establishment of a comprehensive systematic vocational assessment system for secretaries was a milestone in the development of ancient secretary system. That kind of supervision was not only applicable to ancient secretaries but is still fairly beneficial to contemporary secretary and the development of secretary vocation.

\section{Basic Features of the Ancient Vocational Assessment System for Secretaries}

According to The Way of Being an Official in the Bamboo Slips of the Qin Dynasty Unearthed in Yunmeng of Yunnan, in line with the idea that "a wise ruler first manages the officials then the 
people" [3], the Qin Dynasty laid down a nationwide vocational assessment system for secretaries after establishment of the regime, which was deemed as the earliest ancient vocational assessment system for secretaries in China and started the ancient vocational assessment of secretaries. Since then, the rulers of all dynasties had improved or supplemented their respective vocational assessment systems for secretaries on the basis of that of the previous dynasty.

Responsibility System of Dedicated Personnel and Office and Solemnization of Assessment System. Over the ancient dynasties, the power to conduct vocational assessment of secretaries had always been in the hands of the ruling class, and the establishment of assessment principal post was the epitome of the rulers' emphasis on vocational assessment of secretaries. In the Han Dynasty, the vocational assessment of secretaries was divided into two levels, i.e., prefecture \& state and county government. Secretaries at the level of prefecture \& state were subject to the assessment by prefecture chief or prime minister, while those below county government were assessed by county magistrate. In the Tang Dynasty, the officials in charge of assessment were defined as assessment director and assessment assistant director. In the Song and Yuan Dynasties, there were not only dedicated personnel responsible for vocational assessment of secretaries but also Office of Official Examination and Office of Personnel Assessment specially set up for relevant work, which eliminated the possibility of examination result change by the chief official for personal reasons to a large extent and further solemnized the vocational assessment system for secretaries.

Adherence to "Rewarding the Good and Punishing the Bad" to Urge Secretary Personnel. From the Qin Dynasty to the Qing Dynasty, the principle of "rewarding the good and punishing the bad" had always been stuck to in the vocational assessment of secretaries. Promotion to a higher rank was the main form of rewards to those certified to be excellent in the assessments. In the Qin Dynasty, those abiding by "five good practices" could be promoted and even raised to the nobility. In the Tang Dynasty, those rated above the grade of "Below Average" could be promoted by one or two ranks according to specific grades. Directly related to the rated grade and the number and severity of regulations violated, punishments ranged from fine and salary reduction in less severe cases to demotion and even death penalty sometimes in serious cases. For example, in the Qing Dynasty, if "corruption" in the "eight rules" (on corruption, cruelty, inactivity, imprudence, oldness, disease, flippancy, and incompetence) was verified during the assessment, bribes of merely ten taels of silver would lead to a death penalty.

Gradual Expansion and Improvement of Assessment Contents. The contents of vocational assessment of secretaries were basically kept stable in the ancient dynasties and mainly focused on morality and conduct, in spite of the slight difference in presentations of these two dimensions during different periods.

The assessment criteria for secretaries were classified into "five good practices" and "five faults" in the Qin Dynasty. The "five good practices" referred to being faithful to the court and respectful to the higher level, being incorruptible, dealing with things prudently and properly, doing good things for the nation and the people, and being courteous; the "five faults" referred to indulging in exaggerations, boasting of credits instead of being down-to-earth, being self-assertive and acting beyond the due authority, defying superiors, and scorning scholars but highly valuing money. In the Tang Dynasty, the criteria were refined into "four good practices" and "27 bests" [4]. The part of "investigation" was established in the Ming Dynasty to specially assess the professional ethics, competence, and work style of secretaries, which were known as "eight criteria". The "eight criteria" (renamed "eight rules") were still adopted in the Qing Dynasty and combined with "four items" (i.e., "talent", "morality", "performance", and "age", respectively meaning knowledge \& talent, conduct \& morality, work merits \& achievements, and age \& qualification). Thus it can be seen that the contents of assessment had generally gone through a process of constant expansion and innovation and the criteria for professional ethics were gradually raised in the assessments.

Evolution of Assessment Process towards Fairness and Justness. The vocational assessments of secretaries became fair, just, and scientific step by step from the chief official responsibility system in the Qin and Han Dynasties to the completion of assessment procedures in the subsequent dynasties. In the Tang Dynasty, links like "book examination", "mutual evaluation", "publicity", 
"appeal", and "supplementation and correction" were added in the assessment, and the specific process was: the secretary writes down his own moral performance and conducts in the past year, which will be read by the chief official in public; then the grade of current secretary will be determined by relevant personnel through evaluation and discussion and posted at the gate of government office for three days. The secretary may propose an objection against any improper part, or others may make supplementation and correction. In the Song Dynasty, the assessment procedure was started with "performance recording", followed by "official assessment", meaning that a secretary would be preliminarily assessed by his chief official, and then, relevant materials would be collected and sent to the Office of Official Examination and the Office of Personnel Assessment; the final review results would be taken as the sole basis for reward or punishment of the secretary. In the Yuan Dynasty, secretaries participating in assessment needed to fill out a form called "Lizi" (similar to a personal appraisal form nowadays) that covered contents like name, family background, resume, merits \& demerits, and moral and ability performance and then submit the form to the superiors for review.

Institutionalization of Assessment Time. At first, the vocational assessment of secretaries was carried out on an irregular basis. The Qin Dynasty only specified the contents of assessment but didn't define the time span, and it was not until the Han Dynasty that the cycles of vocational assessments of secretaries were fixed, that was, "regular assessment" once a year and "major assessment" once every three years, among which a "major assessment" was the aggregate of "regular assessments" carried out in the past three years. That cycle was basically followed in the later dynasties despite the slight difference in the time length of period. For instance, in the Tang Dynasty, the frequency of "a minor assessment once a year and a major one once every three years" was adjusted to "a minor assessment once a year and a major one once every five years". The establishment of assessment cycle contributed to identifying the working performance of secretaries and marked the progress in the vocational assessment of secretaries.

Diversification of Ratings. The vocational assessments of secretaries in all dynasties differed the most in the aspect of ratings. In the Han Dynasty, either "regular assessment" or "major assessment" had two grades, namely, "good" and "poor". The ratings were increased to nine grades in the Tang Dynasty, namely, "Superior among the Superior", "Middling among the Superior", "Inferior among the Superior", "Above Average", "Average", "Below Average", "Superior among the Inferior", "Middling among the Inferior", and "Inferior among the Inferior". A secretary could be promoted by one rank if rated at the grade of "Average" in the overall appraisal of four minor assessments or by two ranks if rated above the grade of "Inferior of the Superior" in the same appraisal; in contrary, those rated at the grade of "Below Average" and below would be subject to demotion or salary reduction. In the Ming Dynasty, assessments were conducted three times within nine years, and the grades were changed into "Competent", "Common", and "Incompetent"; written examination was also added, and the final rating was made by reference to the assessment results.

\section{Current Situation and Problems in the Contemporary Vocational Assessment System for Secretaries}

The contemporary secretary system has made great progress along with the vigorous development of secretary vocation. Based on full consideration given to the national conditions and by learning from foreign experience, relevant departments and secretary industry of China have unveiled a series of measures for secretary system reform, among which the establishment and implementation of vocational admittance examination system for secretaries is a significant step in the development of contemporary secretary system. However, there are certain problems in the vocational assessment of secretaries.

Much Attention is Paid to the Selection of Secretary Personnel Than the Vocational Assessment of Secretaries. China successively issued the Vocational Skill Standards for Secretaries (Trial) and the National Codes for Vocational Skill Appraisal (Secretary) in 1997 and organized the first secretary qualification appraisal participated in by ten autonomous regions, cities, and provinces in Sept. of 1998, marking secretary vocation was eventually recognized by the state 
and society. The integration with the international vocational qualification of secretaries remarkably raised the international status of China in terms of secretary discipline and secretary vocation. However, over nearly two decades from the establishment of secretary qualification appraisal system till now, there has been no well-established vocational assessment system for secretaries, giving rise to the current situation of focusing on selection but neglecting assessment. By contrast, there are not only sound practitioners' qualification appraisal but also annual verification of vocational qualification for vocations like tour guide, journalist, etc., favorably propelling the practitioners to learn and improve themselves continuously. The lack of vocational assessment system for secretaries is, by comparison, the bottleneck constraining the sustainable development of secretary vocation.

There is no Unified Standard for Secretary Vocational Assessment, and Employers Adopt their Own Standards. Because there is no unified vocational assessment system for secretaries or unified assessment criteria, employers all take the assessment criteria for general administrative posts as the basis of secretary assessment. However, it is determined by the characteristics of secretary vocation, such as assistant nature, diversified contents of work, and collectivization of working achievements, that if secretaries are assessed as per the criteria for general administrative posts, the assessment will be unable to reach a fair and rational conclusion in a scientific way. Moreover, position promotion is closely related to the results of assessment; thus secretaries have no competitive advantage in promotion, which is adverse to the career development of a secretary.

Skill-based Selection is Valued over Professional Ethics. To attach importance to and cultivate the professional ethics of secretary is required by the particularity of secretary vocation, but contemporary selection of secretaries focuses too much on vocational skills and ignores the evaluation on professional ethics. Especially in the secretary qualification appraisal, the evaluation on professional ethics only accounts for about $10 \%$ of the overall appraisal. In the specific assessment, the employers also take "tangible and evaluable" performance items as assessment criteria and neglect moral evaluation. Cases of corruption, malpractice, and regulation violation exposed successively in recent years are exactly the manifestations of the neglect of professional ethics guidance and evaluation.

\section{Innovations in the Contemporary Vocational Assessment of Secretaries}

The current situation of contemporary vocational assessment of secretaries requires us to review the existing problems and seek effective solutions and approaches. Due to its long process of development, improvement, and innovation, the ancient vocational assessment system for secretaries has a positive reference significance to the establishment and completion of the contemporary one.

Strengthening the Guidance and Constraint of the Professional Ethics of Secretaries. The ancient vocational assessment of secretaries stressed morality, whereas the contemporary one generally pays attention to practical skills like multiple languages, computer, and office automation operation and ignores professional ethics. A secretary should establish a correct moral outlook; the professional ethics education, in addition to guidance and constraint, of secretaries should be strengthened, which is the basis for the healthy development of secretary vocation.

Intensifying the Supervision and Management over Secretaries. The rulers of all ancient dynasties implemented strict supervision and management over officials, including secretaries. For example, in the Tang Dynasty, supervision channels were opened on an extensive scale, and the Censorate was specially set to supervise officials; officials were not allowed to engage in trade or lending in order to avoid collusion between government officials and businessmen; it was also prescribed that relatives should not work in the same government office and an official should not take office in his native place. Those measures had a restraining and alerting effect on officials and meanwhile prevented official corruption in an appropriate manner. Such supervisory regulations can serve as good reference to the supervision and management over contemporary secretary vocation.

In any country at any time, clean government and anti-corruption are important issues related to the managements over and by officials and concerning a political party's survival, a country's 
prosperity, and people's peaceful and contented life. The particularity and post importance of secretary vocation determine that a secretary always does an ancillary work around his/her leader regardless of the official rank. A secretary gives his/her leader intellectual support via the advising and consulting function and has an inseparable working relationship with his/her leader directly resulting from the ancillary service function; furthermore, the function of dealing with routine matters brings the secretary in touch with a large amount of core working and even confidential contents. The close relationship between a secretary and his/her leader makes the latter the harbor of refuge of the former. Secretary is a factor frequently leading to the corruption cases of leaders at present.

Hence, rigorous supervisory regulations on the vocational assessment of secretaries should be formulated and institutionalized, and secretaries in organizations of different natures should be assessed and supervised in line with relevant regulations. At the same time, a supervisory institution should be built to make secretary supervision normalized and independent, so as to better prevent and punish discipline- and rule-breaking behaviors in the secretary work.

Establishing a Vocational Assessment System for Secretaries. The relatively stable working environment will inevitably breed laziness of persons engaged in secretary vocation for a long term. However, the working contents of a secretary have a wide variety, and the secretary will be unable to cope with the complex work as time passes if he/she doesn't learn and study actively to improve his/her personal qualities and abilities. In the wake of social development and management means advancement, new things, new conditions, and new problems emerge in an endless stream, which also require a secretary to constantly learn and study to cope with the new working environment. Therefore, in the promotion of a secretary, study should be taken as an important criterion. Then, how to impel a secretary to constantly learn professional knowledge and improve his/her professional ability? There is no better method than establishing a vocational assessment system for secretaries. The system can effectively propel secretaries to study every day on the one hand and provide reference basis for the promotion of secretaries on the other hand. More importantly, it can effectively prevent the breeding of "once-for-all" psychology and post inertia of secretaries and make them always keep vigilant and have a strong sense of responsibility and an attitude that keeps pace with the times.

\section{Summary}

In conclusion, implementing vocational assessment of secretaries is an effective way to promote the constant improvement and self-transcendence of secretaries and a strong guarantee for stimulating post enthusiasm and improving substantial working effect. As a result, we should establish a sound vocational assessment system for secretaries and truly put it into practice.

\section{References}

[1] S. S. Yang: Secretary Vol. 7 (2009), p. 6

[2] F. G. Meng and L. Li: Journal of Teachers College Qingdao University Vol.2 (2000), p.47

[3] G. G. Qing: Journal of Southwest China Normal University Vol. 2(2003), p.1

[4] Z. C. Ling: Secretary's Companion Vol.3 (2008), p. 37. 